\title{
The myofibroblast, biological activities and roles in eye repair and fibrosis. A focus on healing mechanisms in avascular cornea
}

\author{
Maxime Rocher ${ }^{1} \cdot$ Pierre-Yves Robert $^{1} \cdot$ Alexis Desmoulière $^{2}$
}

Received: 30 September 2019 / Revised: 17 October 2019 / Accepted: 24 October 2019 / Published online: 25 November 2019

(c) The Royal College of Ophthalmologists 2019

\begin{abstract}
Tissue healing is one of the mysteries of modern medicine. Healing involves complex processes and many cellular types, amongst which the myofibroblast plays a major role. In the eye, when needed, myofibroblasts can be found from the cornea to the retina, derived from a wide variety of different cells, and aimed at effectively repairing tissue damage. Myofibroblast differentiation requires transforming growth factor (TGF)- $\beta 1$, the presence of specific extracellular matrix components such as the ED-A domain of fibronectin, and mechanical tension. Control of this process may, in some cases, be abnormal leading to development of fibrotic tissue, which alters and compromises the integrity of the original tissue. The eye is no exception to this rule with normal visual function, a highly demanding process, only possible in a fully integrated organ. The cornea, a transparent protective tissue and first dioptre of the eye, has the particularity of being entirely avascular and very richly innervated under normal physiological conditions. However, these anatomical features do not prevent it from developing myofibroblasts in the event of a deep corneal lesion. Activated by growth factors such as TGF- $\beta 1$ and platelet-derived growth factor from the aqueous humour, tears or corneal epithelial cells, myofibroblasts can cause corneal scarring, sometimes with devastating consequences. Understanding the factors involved in healing and its signalling pathways, will potentially enable us to control corneal healing in the future, and thus avoid fibrotic ocular surface disease and the blindness that this may induce. Currently, this issue is the subject of very active research and development with the aim of discovering new antifibrotic therapies.
\end{abstract}

\section{Introduction}

Tissue repair or healing, which remained poorly understood for a long time, is one of the many mysteries of medicine. Scientific advances at the cellular and molecular level have led to a better understanding of the biological and pathophysiological mechanisms of wound healing. The myofibroblast, a real cornerstone of tissue repair, is the origin of significant contractile forces, via linking the extracellular matrix (ECM) to its cytoskeleton. In scar tissue this has anatomical but also functional consequences, particularly in those tissues whose properties depend on the tensile characteristics of the tissue [1]. The eye is not an exception to

Alexis Desmoulière

alexis.desmouliere@unilim.fr

1 Department of Ophthalmology, Limoges University Hospital, F87000 Limoges, France

2 Department of Physiology and EA 6309, Faculties of Medicine and Pharmacy, University of Limoges, F-87000 Limoges, France this rule [2]. Indeed, the cornea is a perfect example of the anatomo-functional interweaving necessary for this avascular and transparent structure to transmit, diffuse and refract light rays. If this structural organization is modified through the presence or activity of cells involved in healing, optical properties can be affected leading to a decrease in vision and leading eventually to blindness [3].

Knowledge of the structure and activity of myofibroblasts has progressed significantly in recent years, giving rise to promising therapeutic strategies, the aim of which is to limit the action of myofibroblastic cells in a variety of important pathologies. The purpose of this article is to give an overview of myofibroblast biological activities and to underline the roles of myofibroblasts in normal and pathological healing processes in the eye, with a focus on corneal repair.

\section{What is a myofibroblast?}

Classically, it has been accepted that myofibroblasts derive from fibroblasts, a cell type found in most organs of the human body. Morphologically fusiform or star-shaped, 
myofibroblasts are relatively elongated cells, about 20-30 $\mu \mathrm{m}$ long, rich in protein and energy-producing organelles, making them very metabolically active within the connective tissue. They possess a highly developed cytoskeleton, including a specific network of actin isoforms and intermediate filaments. Myofibroblasts also play an important supporting role thanks to the secretion and regulation of ECM components (Fig. 1), and then strong interactions exist between the ECM and the cytoskeleton via cell attachment proteins. They are highly metabolically active, allowing them to maintain the homeostasis of ECM during tissue repair processes. Aside from their important role in regulation of the ECM, myofibroblasts also play roles in immunomodulation and angiogenesis [4].

Embryologically, myofibroblasts have a mesenchymal origin and can exhibit different a range of phenotypes from non-contractile fibroblasts to truly contractile myofibroblasts as well as numerous intermediate phenotypes including the proto-myofibroblast [5]. As underlined above, in most cases, the myofibroblast is directly derived from the fibroblast. Though similar in makeup to fibroblasts, they differ essentially in the presence of $\alpha$-smooth muscle actin (the actin isoform typically found in contractile smooth muscle cells), microfilaments are also associated with tight junctions, linking them together and conferring contractile properties within the scar tissue (Fig. 1). This contractile activity, combined with cellular connections to the ECM and to each other, enables the edges of a wound to be brought together. In summary, these cells play an important role in plasticity, migration and cell mobility during tissue repair in addition to their ECM-regulatory functions.

\section{Origin of myofibroblasts and factors involved in their activation}

One of the most interesting characteristics of myofibroblasts is the fact that they can be derived from a very large variety of different cell types [6]. Apart from local fibroblasts, other cells can also be the origin of myofibroblasts, including pericytes, hepatic stellate cells [7] or keratocytes in the eye [3]. Bone marrow may also be a source of myofibroblasts via circulating stem cells and/or fibrocytes [8]. Lastly, it has been suggested that the process of epithelial or endothelial-mesenchymal transition, resulting from a dedifferentiation of epithelial or endothelial cells, can in some situations be the origin of myofibroblasts [9].

During tissue repair, myofibroblasts appear during the formation of granulation tissue that is responsible for replacement of the damaged or lost tissue. Prior to this phase, during the vascular and inflammatory phases, numerous factors are released stimulating angiogenesis in this newly formed tissue and also inducing myofibroblast

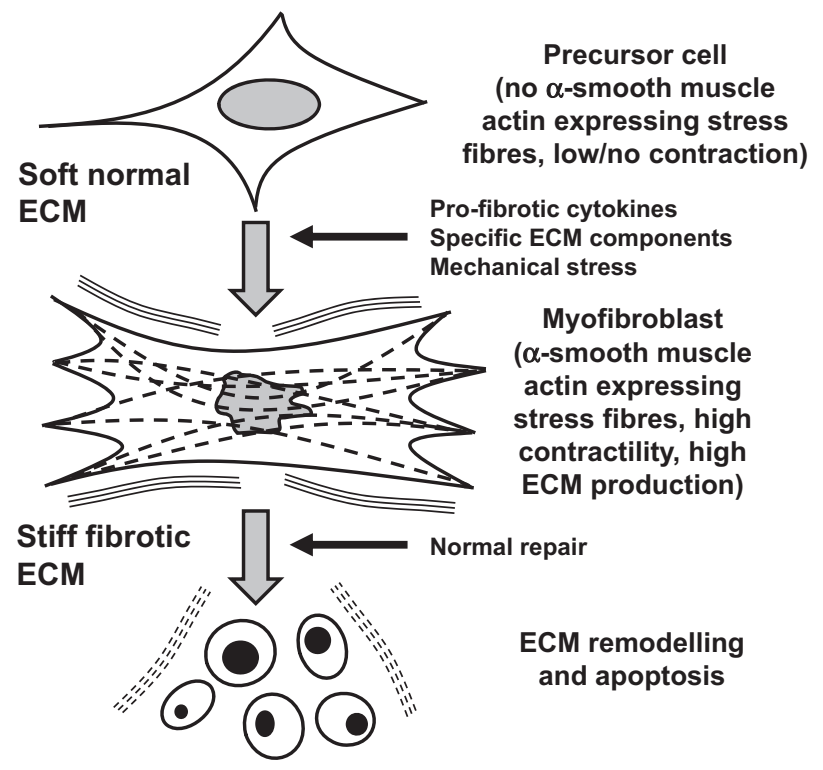

Fig. 1 Illustration showing the appearance of the myofibroblast phenotype during normal repair conditions. Fully differentiated myofibroblasts possess stress fibres expressing $\alpha$-smooth muscle actin (dotted lines) and secrete important amount of extracellular matrix (ECM). Pro-fibrotic cytokines such as transforming growth factor- $\beta 1$, ECM components such as ED-A fibronectin and the mechanical microenvironment are all involved in myofibroblastic differentiation. Myofibroblasts are highly contractile cells that stiffen the ECM, leading to an activation of pro-fibrotic growth factors, further stimulating the activation of new myofibroblasts

differentiation. Among these factors, platelet-derived growth factor (PDGF) and more importantly, transforming growth factor (TGF)- $\beta 1$, play major roles. The migration of myofibroblast precursor cells, endothelial cells and pericytes is supported by PDGF, while TGF- $\beta 1$ is involved in induction of $\alpha$-smooth muscle actin expression by myofibroblasts and also stimulates increased synthesis and secretion of ECM [10]. Interestingly, to obtain complete myofibroblast differentiation, in addition to TGF- $\beta 1$, specific extracellular components including the ED-A domain of fibronectin, and mechanical stress are also necessary (Fig. 1) [11]. In fact, depending on the stiffness or compliance of the ECM, TGF- $\beta 1$ may be bound and trapped in a large latent complex (also containing latency TGF- $\beta$ binding protein and latency associated peptide) in the case of soft compliant ECM, while it is cleaved and released if the ECM is stiff. During the last phase of tissue repair leading to scar formation, there is remodelling of the granulation tissue due to the action of matrix metalloproteinases and the disappearance of cells, including myofibroblasts and vascular cells, by apoptosis (Fig. 1) [12]. Though the first phase of tissue repair is mainly devoted to inflammation, throughout the tissue repair process, inflammatory cells and particularly macrophages, which secrete TGF- $\beta 1$ and proteases, orchestrate the relationships between myofibroblasts 
and the ECM, in particular macrophages that are in close contact with contractile myofibroblasts modulate both ECM composition and biophysical state [13, 14]. Lastly, in pathological situations where chronic activation of myofibroblast activation develops, excessive scarring leading to fibrosis can be observed [1].

\section{Myofibroblasts in the eye}

One of our most precious sense organs, the eye is one organ in the body where the integrity of all tissues is essential to maintain a very demanding function, sight. This function is dependent on a multitude of factors, including stable cellular and molecular regulation that maintains the original tissue integrity and architecture. In the eye, myofibroblasts are also present and can behave similarly to other myofibroblasts in the human body. As the cornerstone of wound healing, they can be activated in variety of ocular tissues despite the immune privilege of the organ. Such activation of myofibroblasts can compromise the perfect architecture of the various ocular tissues and thus profoundly change visual function.

The myofibroblast is therefore implicated in many eye diseases. At the level of the conjunctiva, it is involved in the pathogenesis of fibrotic conjunctivitis [15] or pterygia $[16,17]$. The development and progression of this degenerative fibrovascular sub-epithelial protrusion is multifactorial, with a link between UV irradiation and overexpression of heparin-binding epidermal growth factorlike growth factor and of TGF- $\beta$ [18], a well-known differentiation factor for myofibroblasts (see above).

The epithelial-mesenchymal transition process under the influence of TGF- $\beta$ leads to a transdifferentiation of lens epithelial cells into myofibroblasts, which then produce an aberrant ECM. The aberrant ECM is then responsible for opacification of the anterior lens capsule [19], as well as opacification of the posterior capsule secondary to residual lens epithelial cells after cataract surgery [20] or using an in vitro capsular bag model [21]. Interestingly, in the posterior capsule opacification observed after surgery (secondary cataract), contractile myofibroblasts also cause wrinkles on the posterior capsule [22]. Several factors such as eye trauma [23], uveitis [21] or atopic dermatitis [24, 25] have been identified as possible causes of opacification of the anterior lens capsule.

Chronic glaucoma is a progressive optic neuropathy characterized by papillary excavation, secondary to the loss of the retinal nerve fibre layer with ocular hypertonia.

An extensive deposition of ECM, associated with cellular and molecular events (including myofibroblast activation), leads to tissue fibrosis and stiffening [26]. Myofibroblasts are found in the anterior chamber and induce morphological changes in the trabeculum, thus reducing the evacuation of aqueous humour and this is in turn responsible for an increase in pressure [27, 28]. These cells, at the conjunctival level, also cause excessive scarring in the flaps and filter bubbles of glaucoma filtration surgery [29], often resulting in unsatisfactory results in terms of pressure and possibly requiring needling in post-operative follow-up, with subconjunctival injection of mitomycin $\mathrm{C}$ for its antimetabolite and antifibrotic properties [30].

The retina, a neurosensory tissue that lines the interior of the globe, can also be subject to the effects of myofibroblasts. These cells, activated by growth factors provided by neovascularization following a rupture of the blood-retinal barrier, are responsible for sub-retinal fibrosis of age-related macular degeneration [31], fibrovascular membranes in diabetic retinopathy [32, 33], and for vitreoretinal proliferation observed as a result of rhegmatogenic retinal detachment after transdifferentiation of pigment epithelial cells $[34,35]$.

The myofibroblast is also present in the orbit and is involved in the spectrum of Graves' orbitopathies, driven by TGF- $\beta$ again playing a key role in both orbital inflammation and tissue remodelling [36].

\section{Myofibroblasts in corneal repair}

As underlined above, myofibroblasts are found in all ocular tissues as a key element of the healing process and they are very active particularly in the cornea. The cornea being the first dioptre of the eye is one of the components of the ocular surface and is therefore subjected to the environment and to external insults. To maintain its privileged avascular structure, the cornea possesses its own tissue repair mechanisms. The epithelium is an ideal first physiological barrier protecting the eye from pathogenic microorganisms. However, superficial corneal trauma leads to an epithelial defect for which the speed of healing under physiological conditions is aided by epithelial cell migration and increased epithelial proliferation (Fig. 2) [37]. The cells for this are derived from a pool of corneal-limbic stem cells and rapid healing helps to avoid both microbial infection and additional trauma to the underlying stroma. Good healing of superficial corneal wounds seems to provide a very good prognosis for recovery of vision.

The same situation is not true in the case of deeper corneal lesions where there is stromal damage, for example seen in corneal ulcers. In this case, restoration of vision is threatened by a lack of healing of the basement membrane, by the formation of a stromal haze, by sub-epithelial fibrosis or epithelial keratinization (Fig. 2) [37, 38].

As the third leading cause of blindness in the world among the working-age population [39], understanding 
Fig. 2 Schematic diagram of the corneal wound healing process. a Implementation of the healing process. Corneal injury involves rupture of the corneal epithelial layer and of the Bowman's membrane. The anterior stroma therefore is highly exposed to cytokines and others growth factors, particularly transforming growth factor- $\beta 1$ (TGFß1) and platelet-derived growth factor (PDGF), from corneal epithelial cells, aqueous humour, conjunctiva and tears. Under the influence of active TGFß1, keratocytes of the anterior stroma and/or cells derived from bone marrow, which normally are in a quiescent state, transdifferentiate into myofibroblasts, proliferate and then spread to the site of the lesion by centripetal migration. b Physiological wound healing. Epithelial cells migrate and epithelial proliferation appears. Myofibroblasts synthesize new extracellular matrix (ECM). In the absence of pathological phenomena, myofibroblasts disappear by interleukin (IL)-1induced apoptosis and tissue transparency is maintained. c Pathological conditions. Myofibroblasts live on and continue to secrete excessive amounts of aberrant ECM proteins. This situation leads to fibrosis and the clinical onset of corneal opacification. This chronic corneal injury subsequently induces corneal neoangiogenesis

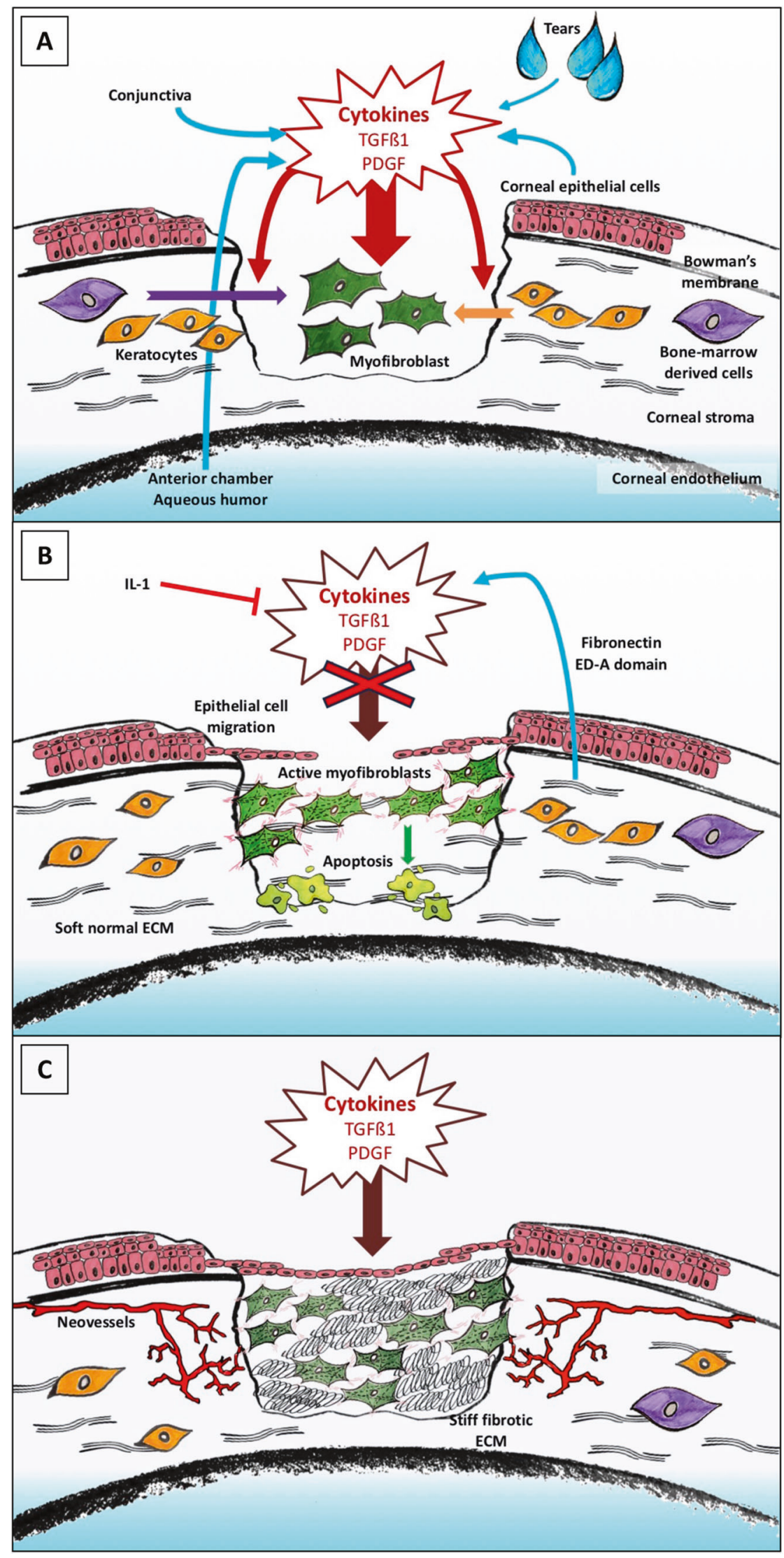


corneal scarring is essential for the management of patients with corneal trauma. Indeed, the stages of tissue repair are slightly rearranged for the cornea with differences in the inflammatory and vascular phase. This phase, which results in temporary matrix deposition and the secretion of proinflammatory factors, cannot take place in this avascular tissue.

After a corneal wound, the healing sequence is complex and finely regulated: inflammatory cells and cytokines are present in the acute phase in the cornea but arrive via nonvascular paths. In part secreted by corneal cells, particularly epithelial cells [40], these growth factors are also provided by the aqueous humour, in the case of posterior lesions of the cornea [41], and to a lesser extent by tears and the conjunctiva (Fig. 2) [42-44]. Among the most active factors are TGF- $\beta$ and PDGF, to which corneal cells are very much exposed if the Bowman layer is affected [25]. Under the influence of active TGF- $\beta 1$ [10], keratocytes of the anterior stroma and/or cells derived from bone marrow, which would normally be in a quiescent state, transdifferentiate into myofibroblasts, proliferate and then spread to the site of the lesion by centripetal migration (Fig. 2). As in other tissues, the maintenance of an effective level of TGF- $\beta 1$ is ensured, among other means, by the presence of the ED-A domain of fibronectin in the ECM [45] and mechanical tensile forces, exerted by myofibroblast contraction on the ECM, releases this growth factor. These cells then cover the wound and begin to synthesize new ECM. While neoangiogenesis is a mandatory and normal physiological phase of early inflammation in all tissues of the body, in the case of the cornea, it is supplemented by the haemato-aqueous barrier.

Once the healing of a corneal lesion is complete, and in the absence of pathological phenomena, myofibroblasts disappear by interleukin-1-induced apoptosis [46]. This regulatory factor, produced by stromal cells, allows the recolonization of the anterior stroma by keratocytes. These cells will then remodel the ECM at the wound site by the action of metalloproteinases and thus restructure the corneal tissue architecture, which is essential to restore transparency and achieve corneal integrity (Fig. 2).

In certain pathological conditions, the persistence of TGF- $\beta 1$ can be problematic because it contributes to the maintenance of myofibroblasts that continue to secrete excessive amounts of aberrant ECM proteins. This situation leads to fibrosis repairing tissue and the clinical onset of corneal opacification, which may persist long after the myofibroblasts have disappeared from the lesion site (Fig. 2) [47]. The impact on visual function is, of course, highly variable, being asymptomatic for the most discrete impairments, but ranging from photophobia and irregular astigmatism to legal blindness in some cases of major corneal fibrosis located in the visual axis. This chronic

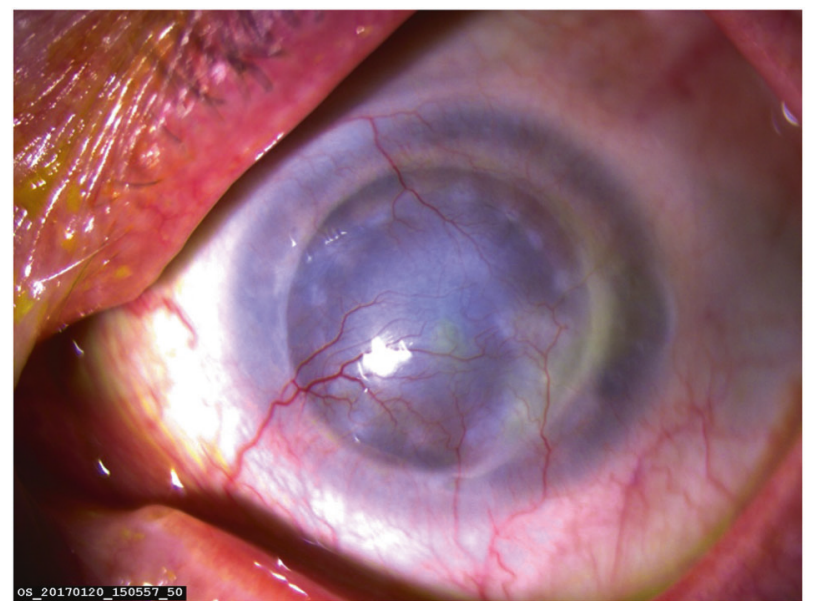

Fig. 3 Corneal neovascularization in pathological situations. Recurrent stromal herpetic keratitis on corneal graft, 8 years after penetrating keratoplasty. This leads to corneal opacities responsible for a major loss of vision for the patient and a very probable risk of graft rejection

corneal injury subsequently leads to corneal neoangiogenesis (Figs. 2 and 3). Pathological situations where there is development of new corneal vessels are responsible for corneal diseases that also result in damage to vision. In these pathologies, the epithelium and epithelial basement membrane and/or the endothelium and Descemet's basement membrane can be disrupted. Resolution of fibrosis and the restoration of stromal transparency appears to depend, in part, on the reconstruction/regeneration of these basement membranes [48].

\section{Role of corneal innervation}

In the body, the peripheral nervous system influences a variety of physiological and pathophysiological functions. In the skin, autonomic nerve fibres derived from sympathetic (cholinergic) neurons are present, playing a role particularly in the regulation of body temperature. However, the skin is most importantly a highly sensitive organ, densely innervated with different types of sensory nerve endings, which are responsible for pain, temperature and touch sensation [49].

Lesions to the peripheral nervous system that are observed in clinical situations influence tissue repair, which can result in chronic wounds within the affected area, as is often seen in the skin. Indeed, patients with cutaneous sensory defects may develop ulcers that fail to heal (e.g. diabetic neuropathy). In addition, after surgical resection of nerves in animal models, delayed healing has been observed, suggesting that neurogenic stimuli profoundly affect tissue repair after injury. Overall these data clearly indicate that innervation and neuromediators play a major role in tissue repair processes [50]. 
Fig. 4 Sub-basal nervous plexus in a healthy patient, shown using confocal microscopy. The fibres are derived from the subepithelial nerve plexus after crossing the Bowman layer. This combined image shows the complex architecture and interconnections of nerve fibres within the sub-basal area, constituting, in the form of a vortex, one of the densest nervous networks in the organism

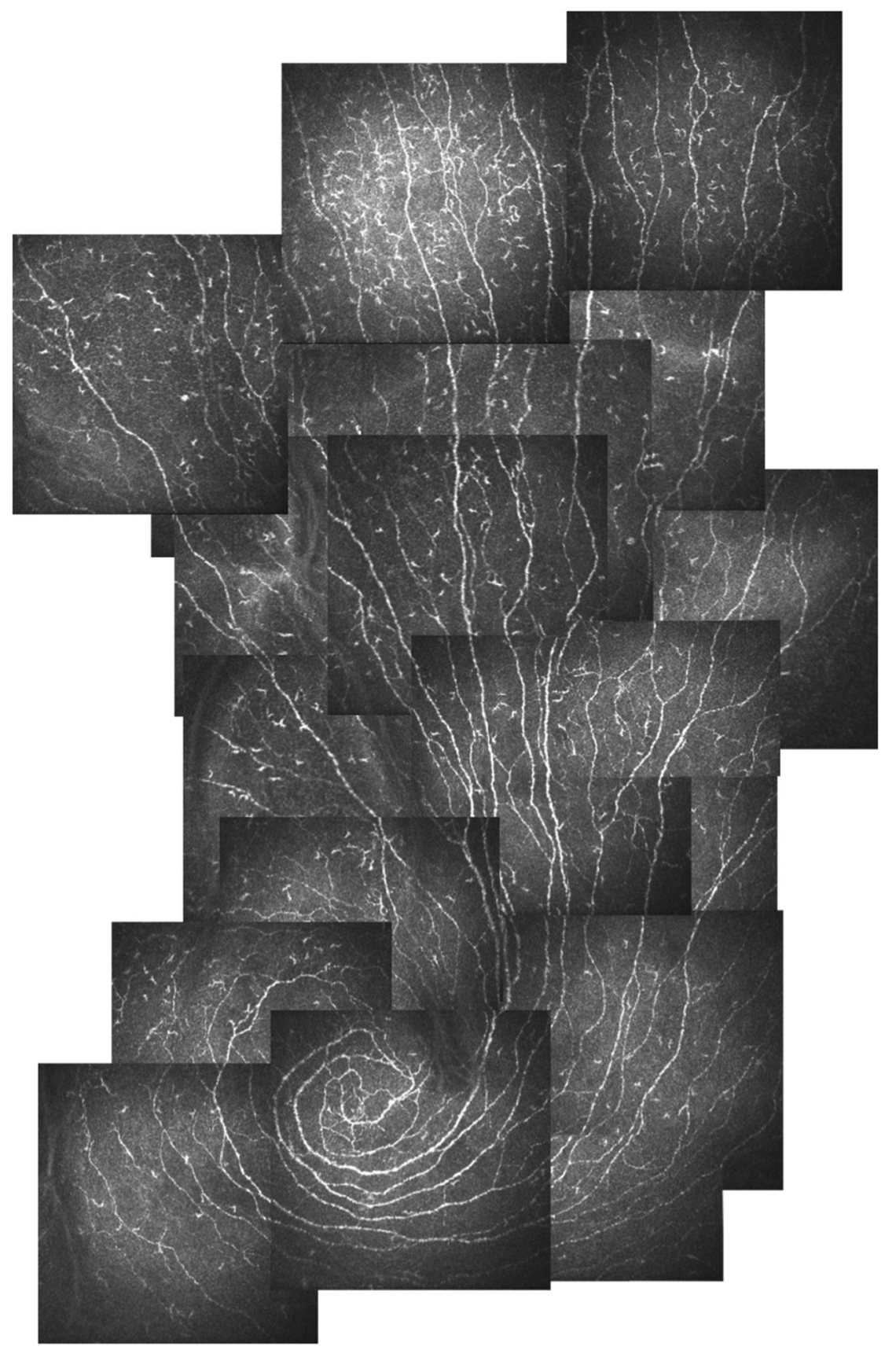

As discussed above, in the eye, in most cases the repair process follows a classical course similar to that seen in other parts of the body. However, in the cornea, which is devoid of blood and lymphatic vessels, the first phase (traditionally referred to as the vascular and inflammatory phase) is one phase that differs compared with the phases seen in other tissues. Interestingly, the cornea contains a dense network of autonomic and sensory nerve fibres [51]. Indeed, it seems that the cornea is the most densely innervated structure in the human body (Fig. 4). As in the skin, corneal nerves are involved in pain, temperature and touch sensation and play important roles in the blink reflex, and in tear production and secretion to achieve normal corneo-conjunctival lubrication [52].

Reinnervation of the cornea following disease, injury or surgery is an important point to consider. Moreover we can also suggest that innervation counterbalances, at least in part, the absence of blood vessels and is responsible after damage for supplying many neuromediators, which replace the soluble factors (cytokines and growth factors) classically provided by vascular cells during the first inflammatory and vascular phases of tissue repair. 


\section{Conclusion and perspectives}

Good visual function is based on perfect tissue integrity of the eye. In this equation, the myofibroblast has good intentions but tends to do more harm than good. Indeed, after an eye injury, myofibroblast activation helps to limit the damage and preserve a certain degree of tissue integrity, at the cost of scar formation which has potential consequences on vision. When visual degradation becomes disabling, the available therapeutic solutions include surgery, especially corneal transplantation, where current technical prowess allows lamellar grafts to replace only the altered part of the cornea [53], or phacoemulsification of the lens in the event of cataract replacement by an intraocular implant [54]. The current treatments using surgery, in some cases preventive surgery such as refractive and glaucoma surgeries, combined with the use of a cytotoxic antibiotic, mitomycin $\mathrm{C}$, for its immunomodulatory properties on the sub-epithelial haze [55-57], and on bleb scarring [30], point to the management of fibrosis not lacking in future therapeutic strategies.

The discovery of the molecular mechanisms involved in modifying cellular responses has increased our understanding of healing and scarring. Despite the heterogeneity of their origins, all differentiated myofibroblasts perform very similar functions, such as tissue remodelling and ECM synthesis. The processes regulating these functions would therefore seem to be promising therapeutic targets [58]. Indeed, it is now possible to put our finger on the biochemical signalling pathways involved in this phenomenon. It therefore seems appropriate to now try to control the molecular mediators and epigenetic regulators involved in order to affect the pathogenesis of ocular fibrosis [59].

However, this is not an easy task. Indeed, even for TGF$\beta 1$, a molecule whose involvement in tissue healing has long been demonstrated, the complexity of its signalling pathways still means that the perfect understanding of its mechanisms is elusive. This growth factor has a dual role in epithelial-mesenchymal transdifferentiation in various fibrotic diseases and in normal physiological healing, making it an ideal target. At the wound site, it would be necessary to be able to prevent transdifferentiation of myofibroblasts while preserving the pathways required for homeostasis and healing of ocular wounds [2]. This is the approach used, for example, in recent gene therapies targeting SMAD7, which regulates the expression of ECM and myogenic proteins. There are close links between the multiple signalling cascades, transcription factors and inhibition factors common to the different ocular tissues where SMAD7 in particular could be targeted for improvement of corneal stromal fibrosis [60], endothelial wound healing [61], and post-traumatic crystalline fibrosis [62]. These new therapies will also need to have effects on ECM remodelling and replacement by degrading fibrotic matrix and then delivering cells with regenerative potential to recreate a functional ECM close to that of the original tissue [63].

Current research has also looked at using stem cell-based therapies, isolated from different non-ocular tissues [64], to support corneal regeneration by accelerating the healing of corneal wounds, compensating for the loss of epithelial cells, keratocytes and endothelial cells in certain diseases and allowing the repair of the ECM, which must be regular and transparent. In addition, new techniques of treatment delivery could improve the efficacy of the treatment [65].

Finally, the area of antifibrotic treatment is now expanding for patients with the goal of inhibiting pathological aspects of ocular tissue fibrosis without affecting the primary mechanisms of wound healing and tissue restoration. This still represents a major challenge but will be essential for the rehabilitation of visual function and thus limiting secondary blindness that can result from these disorders.

Acknowledgements The authors thank K Asselineau (Department of Ophthalmology, Limoges University Hospital, France) for the production of Fig. 4.

\section{Compliance with ethical standards}

Conflict of interest The authors declare that they have no conflict of interest.

Publisher's note Springer Nature remains neutral with regard to jurisdictional claims in published maps and institutional affiliations.

\section{References}

1. Darby IA, Zakuan N, Billet F, Desmoulière A. The myofibroblast, a key cell in normal and pathological tissue repair. Cell Mol Life Sci. 2016;73:1145-57.

2. Shu DY, Lovicu FJ. Myofibroblast transdifferentiation: the dark force in ocular wound healing and fibrosis. Prog Retin Eye Res. 2017;60:44-65.

3. Torricelli AA, Santhanam A, Wu J, Singh V, Wilson SE. The corneal fibrosis response to epithelial-stromal injury. Exp Eye Res. 2016;142:110-8.

4. Yazdani S, Bansal R, Prakash J. Drug targeting to myofibroblasts: implications for fibrosis and cancer. Adv Drug Deliv Rev. 2017;121:101-16.

5. Otranto M, Sarrazy V, Bonté F, Hinz B, Gabbiani G, Desmoulière A. The role of the myofibroblast in tumor stroma remodeling. Cell Adh Migr. 2012;6:203-19.

6. Weiskirchen R, Weiskirchen S, Tacke F. Organ and tissue fibrosis: molecular signals, cellular mechanisms and translational implications. Mol Asp Med. 2019;65:2-15.

7. Hinz B, Phan SH, Thannickal VJ, Prunotto M, Desmoulière A, Varga $\mathrm{J}$, et al. Recent developments in myofibroblast biology: paradigms for connective tissue remodeling. Am J Pathol. 2012;180:1340-55. 
8. Galligan CL, Fish EN. The role of circulating fibrocytes in inflammation and autoimmunity. J Leukoc Biol. 2013;93:45-50.

9. Zeisberg M, Kalluri R. The role of epithelial-to-mesenchymal transition in renal fibrosis. J Mol Med. 2004;82:175-81.

10. Desmoulière A, Geinoz A, Gabbiani F, Gabbiani G. Transforming growth factor-beta 1 induces alpha-smooth muscle actin expression in granulation tissue myofibroblasts and in quiescent and growing cultured fibroblasts. J Cell Biol. 1993; 122:103-11.

11. Hinz B, Darby IA, Gabbiani G, Desmoulière A. The role of the myofibroblast in fibrosis and cancer progression. In: Fusenig NE, Mueller MM, editors. Tumor associated fibroblasts and their matrix. Basel, Switzerland: Springer Nature Switzerland AG; 2011, p. 37-74.

12. Desmoulière A, Redard M, Darby I, Gabbiani G. Apoptosis mediates the decrease in cellularity during the transition between granulation tissue and scar. Am J Pathol. 1995;146:56-66.

13. Gerarduzzi C, Di Battista JA. Myofibroblast repair mechanisms post-inflammatory response: a fibrotic perspective. Inflamm Res. 2017;66:451-65.

14. Pakshir P, Hinz B. The big five in fibrosis: macrophages, myofibroblasts, matrix, mechanics, and miscommunication. Matrix Biol. 2018;68-69:81-93.

15. Roat MI, Sossi G, Lo CY, Thoft RA. Hyperproliferation of conjunctival fibroblasts from patients with cicatricial pemphigoid. Arch Ophthalmol. 1989;107:1064-7.

16. Kato N, Shimmura S, Kawakita T, Miyashita H, Ogawa Y, Yoshida $\mathrm{S}$, et al. Beta-catenin activation and epithelialmesenchymal transition in the pathogenesis of pterygium. Investig Ophthalmol Vis Sci. 2007;48:1511-7.

17. Kato N, Shimmura S. Epithelial-mesenchymal transition in the pathogenesis of pterygium. Inflamm Regen. 2008;28:434-9.

18. Nolan TM, DiGirolamo N, Sachdev NH, Hampartzoumian T, Coroneo MT, Wakefield D. The role of ultraviolet irradiation and heparin-binding epidermal growth factor-like growth factor in the pathogenesis of pterygium. Am J Pathol. 2003;162:567-74.

19. Joo CK, Lee EH, Kim JC, Kim YH, Lee JH, Kim JT, et al. Degeneration and transdifferentiation of human lens epithelial cells in nuclear and anterior polar cataracts. J Cataract Refract Surg. 1999;25:652-8.

20. Wormstone IM, Tamiya S, Anderson I, Duncan G. TGF-beta2induced matrix modification and cell transdifferentiation in the human lens capsular bag. Investig Ophthalmol Vis Sci. 2002;43: 2301-8.

21. Marcantonio JM, Syam PP, Liu CS, Duncan G. Epithelial transdifferentiation and cataract in the human lens. Exp Eye Res. 2003;77:339-46.

22. Lovicu FJ, Shin EH, McAvoy JW. Fibrosis in the lens. Sprouty regulation of TGF $\beta$-signaling prevents lens EMT leading to cataract. Exp Eye Res. 2016;142:92-101.

23. Tang J, Salzman IJ, Sable MD. Traumatic cataract formation after vigorous ocular massage. J Cataract Refract Surg. 2003;29: 1641-2.

24. Sasaki K, Kojima M, Nakaizumi H, Kitagawa K, Yamada Y, Ishizaki H. Early lens changes seen in patients with atopic dermatitis applying image analysis processing of Scheimpflug and specular microscopic images. Ophthalmologica. 1998;212:88-94.

25. Shu DY, Ong K, Lovicu FJ. Histopathology of subcapsular cataract in a patient with atopic dermatitis. Optom Vis Sci. 2017;94:270-6.

26. Liu B, McNally S, Kilpatrick JI, Jarvis SP, O’Brien CJ. Aging and ocular tissue stiffness in glaucoma. Surv Ophthalmol. 2018;63: 56-74.

27. Fuchshofer R, Tamm ER. The role of TGF- $\beta$ in the pathogenesis of primary open-angle glaucoma. Cell Tissue Res. 2012;347: 279-90.
28. Prendes MA, Harris A, Wirostko BM, Gerber AL, Siesky B. The role of transforming growth factor $\beta$ in glaucoma and the therapeutic implications. Br J Ophthalmol. 2013;97:680-6.

29. Schlunck G, Meyer-ter-Vehn T, Klink T, Grehn F. Conjunctival fibrosis following filtering glaucoma surgery. Exp Eye Res. 2016;142:76-82.

30. Amoozgar B, Lin SC, Han Y, Kuo J. A role for antimetabolites in glaucoma tube surgery: current evidence and future directions. Curr Opin Ophthalmol. 2016;27:164-9.

31. Lopez PF, Sippy BD, Lambert HM, Thach AB, Hinton DR. Transdifferentiated retinal pigment epithelial cells are immunoreactive for vascular endothelial growth factor in surgically excised age-related macular degeneration-related choroidal neovascular membranes. Investig Ophthalmol Vis Sci. 1996;37:855-68.

32. Abu El-Asrar AM, Struyf S, Kangave D, Geboes K, Van Damme J. Chemokines in proliferative diabetic retinopathy and proliferative vitreoretinopathy. Eur Cytokine Netw. 2006;17:155-65.

33. Abu El-Asrar AM, De Hertogh G, van den Eynde K, Alam K, Van Raemdonck K, Opdenakker G, et al. Myofibroblasts in proliferative diabetic retinopathy can originate from infiltrating fibrocytes and through endothelial-to-mesenchymal transition (EndoMT). Exp Eye Res. 2015;132:179-89.

34. Wiedemann P. Growth factors in retinal diseases: proliferative vitreoretinopathy, proliferative diabetic retinopathy, and retinal degeneration. Surv Ophthalmol. 1992;36:373-84.

35. Xiao W, Chen X, Liu X, Luo L, Ye S, Liu Y. Trichostatin A, a histone deacetylase inhibitor, suppresses proliferation and epithelial-mesenchymal transition in retinal pigment epithelium cells. J Cell Mol Med. 2014;18:646-55.

36. Dik WA, Virakul S, van Steensel L. Current perspectives on the role of orbital fibroblasts in the pathogenesis of Graves' ophthalmopathy. Exp Eye Res. 2016;142:83-91.

37. Lee KJ, Lee JY, Lee SH, Choi TH. Accelerating repaired basement membrane after bevacizumab treatment on alkali-burned mouse cornea. BMB Rep. 2013;46:195-200.

38. Kawashima M, Kawakita T, Higa K, Satake Y, Omoto M, Tsubota $\mathrm{K}$, et al. Subepithelial corneal fibrosis partially due to epithelial-mesenchymal transition of ocular surface epithelium. Mol Vis. 2010;16:2727-32.

39. Foster A, Resnikoff S. The impact of Vision 2020 on global blindness. Eye. 2005;19:1133-5.

40. Marino GK, Santhiago MR, Santhanam A, Lassance L, Thangavadivel S, Medeiros CS, et al. Epithelial basement membrane injury and regeneration modulates corneal fibrosis after pseudomonas corneal ulcers in rabbits. Exp Eye Res. 2017;161:101-5.

41. Wilson SE, Lloyd SA. Epidermal growth factor and its receptor, basic fibroblast growth factor, transforming growth factor beta-1, and interleukin-1 alpha messenger RNA production in human corneal endothelial cells. Investig Ophthalmol Vis Sci. 1991;32:2747-56.

42. Chaurasia SS, Kaur H, de Medeiros FW, Smith SD, Wilson SE. Dynamics of the expression of intermediate filaments vimentin and desmin during myofibroblast differentiation after corneal injury. Exp Eye Res. 2009;89:133-9.

43. Barbosa FL, Chaurasia SS, Cutler A, Asosingh K, Kaur H, de Medeiros FW, et al. Corneal myofibroblast generation from bone marrow-derived cells. Exp Eye Res. 2010;91:92-96.

44. Singh V, Jaini R, Torricelli AA, Santhiago MR, Singh N, Ambati $\mathrm{BK}$, et al. TGF $\beta$ and PDGF-B signaling blockade inhibits myofibroblast development from both bone marrow-derived and keratocyte-derived precursor cells in vivo. Exp Eye Res. 2014; 121:35-40.

45. Serini G, Bochaton-Piallat ML, Ropraz P, Geinoz A, Borsi L, Zardi L, et al. The fibronectin domain ED-A is crucial for myofibroblastic phenotype induction by transforming growth factorbeta1. J Cell Biol. 1998;142:873-81. 
46. Wilson SE, He YG, Weng J, Li Q, McDowall AW, Vital M, et al. Epithelial injury induces keratocyte apoptosis: hypothesized role for the interleukin-1 system in the modulation of corneal tissue organization and wound healing. Exp Eye Res. 1996;62:325-7.

47. Wilson SE. Corneal myofibroblast biology and pathobiology: generation, persistence, and transparency. Exp Eye Res. 2012;99: 78-88.

48. Medeiros CS, Marino GK, Santhiago MR, Wilson SE. The corneal basement membranes and stromal fibrosis. Investig Ophthalmol Vis Sci. 2018;59:4044-53.

49. Laverdet B, Danigo A, Girard D, Magy L, Demiot C, Desmoulière A. Skin innervation: important roles during normal and pathological cutaneous repair. Histol Histopathol. 2015;30:875-92.

50. Lebonvallet N, Laverdet B, Misery L, Desmoulière A, Girard D. New insights into the roles of myofibroblasts and innervation during skin healing and innovative therapies to improve scar innervation. Exp Dermatol. 2018;27:950-8.

51. Shaheen BS, Bakir M, Jain S. Corneal nerves in health and disease. Surv Ophthalmol. 2014;59:263-85.

52. Creuzot-Garcher C. Lacrimal film and the ocular surface. J Fr Ophtalmol. 2006;29:1053-9.

53. Tan DT, Dart JK, Holland EJ, Kinoshita S. Corneal transplantation. Lancet. 2012;379:1749-61.

54. Liu YC, Wilkins M, Kim T, Malyugin B, Mehta JS. Cataracts. Lancet. 2017;390:600-12.

55. Teus MA, de Benito-Llopis L, Alió JL. Mitomycin C in corneal refractive surgery. Surv Ophthalmol. 2009;54:487-502.

56. Santhiago MR, Netto MV, Wilson SE, Mitomycin C. biological effects and use in refractive surgery. Cornea. 2012;31:311-21.
57. Majmudar PA, Schallhorn SC, Cason JB, Donaldson KE, Kymionis GD, Shtein RM, et al. Mitomycin-C in corneal surface excimer laser ablation techniques: a report by the American Academy of Ophthalmology. Ophthalmology. 2015;122:1085-95.

58. Bochaton-Piallat ML, Gabbiani G, Hinz B. The myofibroblast in wound healing and fibrosis: answered and unanswered questions. F1000Res. 2016;5:752. (F1000 Faculty Rev).

59. Duong TE, Hagood JS. Epigenetic regulation of myofibroblast phenotypes in fibrosis. Curr Pathobiol Rep. 2018;6:79-96.

60. Gupta S, Rodier JT, Sharma A, Giuliano EA, Sinha PR, Hesemann NP, et al. Targeted AAV5-Smad7 gene therapy inhibits corneal scarring in vivo. PLoS ONE. 2017;12:e0172928.

61. Sumioka T, Ikeda K, Okada Y, Yamanaka O, Kitano A, Saika S. Inhibitory effect of blocking TGF-beta/Smad signal on injuryinduced fibrosis of corneal endothelium. Mol Vis. 2008;14: 2272-81.

62. Saika S, Ikeda K, Yamanaka O, Sato M, Muragaki Y, Ohnishi Y, et al. Transient adenoviral gene transfer of Smad7 prevents injuryinduced epithelial-mesenchymal transition of lens epithelium in mice. Lab Investig. 2004;84:1259-70.

63. Walraven M, Hinz B. Therapeutic approaches to control tissue repair and fibrosis: Extracellular matrix as a game changer. Matrix Biol. 2018;71-72:205-24.

64. Bukowiecki A, Hos D, Cursiefen C, Eming SA. Wound-healing studies in cornea and skin: parallels, differences and opportunities. Int J Mol Sci. 2017;18:E1257.

65. Ibrahim Al-Mashahedah AM, Kanwar RK, Kanwar JR. Utility of nanomedicine targeting scar-forming myofibroblasts to attenuate corneal scarring and haze. Nanomed. 2019;14:1049-72. 